\title{
Faces of Dementia “Old Age or Disease? See it Sooner”
}

\author{
Susheel Kumar V Ronad ${ }^{1 *}$, Shrinivas ${ }^{2}$, Chetan Patali ${ }^{3}$, Kiran Kumar T C ${ }^{4}$, Pankaja T C ${ }^{5}$, Rajendra Badesgol ${ }^{6}$, Shridha \\ Gondbal $^{7}$ and Veeresh Nandgaon ${ }^{8}$
}

${ }^{1}$ Departmentof Psychiatric Nursing, DIMHANS, India

${ }^{2}$ Medical Superintendent, DIMHANS, India

${ }^{3}$ Principal of Dhanush institute of Nursing Sciences, India

${ }^{4}$ Departmentof Management Studies, Karnataka Arts College, India

${ }^{5}$ Assistant Professor, RL Law College, India

${ }^{6}$ Department of Police, India

${ }^{7}$ Staff Nurse, Indira Gandhi Children's Hospital, India

${ }^{8}$ Department of Psychiatric, Nursing KLE Institute of Nursing Sciences, India

*Corresponding author: Susheel Kumar V Ronad, Department of Psychiatric Nursing, DIMHANS, India

Submission: 望 January 02, 2018; Published: 眥 June 25, 2018

\section{Introduction}

\section{Facts of your brain}

a) Your brain weighs approximately 3 pounds, but it is the most important organ in your body.

b) (Sight, Smell, Taste, Sound) a physical feeling or perception resulting from something that happens to or comes into contact with the body people objects, and places.

c) You use your brain for language articulation and communication.

d) You use your brain to perform complex tasks.

e) You use your brain to execute body movements.

f) You use your brain for judgment and reasoning.

g) You use your brain to maintain social skills.

\section{Signs and symptoms of old age}

"There are three signs of old age. The first is the loss of memory, the other two I forget". Aging is "benign senile forgetfulness." The signs and symptoms of old age are different from those of Alzheimer's disease. Old age symptoms, manifested in forgetfulness, are simple lapses in memory: Forgetting the name of a person just met not finding the right word or expression while communicating taking more time to learn a new affair or article. Taking longer time to react or respond.

The above symptoms often worsen due to apses may be a nuisance, but never a problem. The changes in behavior are continual and gradual, due to the decrease of brain function, but never problematic. "Another important criterion is the normal cognitive func tion of the brain and its functions also increased anxiety, giving the concern of Alzheimer's and dementia.

\section{Dementia symptoms}

The signs of dementia are many; however, there is no single behavior that can be identified as characteristic of Alzheimer's disease. The following dementia symptoms are usually gradual and progressive until they become problematic in the patient: Lack of concentration and focus (absence or gradual disappearance of memory cues in the brain) Inability to recognize and use proper verbal and non-verbal cues (e.g. a smile) Inability to understand sounds (loss of interest in listening to music and becoming a passive listener) Loss of senses (inability to enjoy good food, to appreciate music or to create art) Inability to understand and identify problems Difficulty in differentiating and prioritizing (poor timing, lack of planning, inability to cope with changes) Reduced daily activity and mobility (dead brain cells requiring little or no stimulation) Social withdrawal (little social interaction, lack of personal hygiene) Inappropriate actions (dressing inappropriately)Difficulty in learning new things Tendency to suspect the activities of others taking place in surrounding environment.

\section{Difference between Normal Aging and Dementia Introduction}

During the process of normal or "healthy" aging, there are natural changes that take place if one is free of any disease. Some changes in the ability to think are considered a normal part of the aging process. Dementia, on the other hand, is not a normal outcome of aging. 


\section{Normal aging}

a) In normal aging, you can expect many skills and abilities to be intact or only slightly different.

b) You will continue to be independent in what are considered daily activities, such as bathing, dressing, driving, and working

c) You may notice memory loss, but you will be able to give details about those incidents of forgetfulness

d) You will be more concerned about this type of memory loss than your close family members.

e) Despite these occasional lapses of forgetfulness, your memory for recent events and conversations will not be a problem

f) You may notice occasional difficulty with finding the right word that you want to use, but your vocabulary will remain rich

g) Also, a part of the aging process will be the annoying problem of getting lost in a familiar place. You may have to give yourself a few moments to remember your way (but you WILL remember)

h) As you age, you may still be able to operate your common household appliances, even if you may be unwilling to learn how to use new devices.

\section{Dementia}

a) Now, contrast the abilities and skills of normal aging stated above with what you can expect with dementia.

b) A person with dementia depends on others for those daily activities that will keep them independent.

c) He or she will not be able to recall incidents of memory loss and may only complain about memory problems if specifically asked.

d) These occasions of memory loss will become more of a concern for close family members than for the person. In addition

e) There may be a noticeable decline in memory for recent events or the ability to maintain a conversation.

f) A person with dementia has considerable difficulty finding and using the right word. The ability to find the right word continues to decline in dementia

g) The person may lose his/her way in what was very familiar territory and sometimes may take hours to find their way back.

h) Also, a person who has even early dementia will not be able to use common appliances and will be unable to learn how to operate even simple new devices.

\section{Difference between Alzheimer's and dementia}

\section{Introduction}

With old age come problems of loss of cognitive abilities, loss of memory, and impairment of the ability to think coherently. These symptoms are broadly classified as dementia while there is another dreaded ailment known as Alzheimer's with similar symptoms that has increased alarmingly across the country in the last few decades. While Alzheimer's is a progressive brain disease, dementia is not called a disease. Their symptoms are also similar, bringing much confusion among the patients who suffer from either of the two. It is extremely necessary to know the real differences between Alzheimer's and Dementia for a proper diagnosis and possible treatment.

\section{Dementia}

a) Dementia is a symptom

b) Dementia is not called a disease

c) Dementia means that there is something wrong with a person's brain, but it does not provide any information about what is causing the memory or cognitive difficulties

d) Can be triggered by brain injury, brain disease (read Alzheimer's), drug or alcohol abuse, and vitamin and hormonal imbalances

e) Dementia is common in old age

f) The most common symptoms of dementia are memory loss, changes in personality, mood swings, confusion, speech problems and a general difficulty in carrying on with day to day activities.

g) Dementia can be reversible or irreversible depending upon what triggers it. If it is caused by vitamin or hormonal imbalances reversal of symptoms is possible.

\section{Alzheimer's disease (AD)}

a) $\mathrm{AD}$ is the cause of the symptom

b) $\mathrm{AD}$ is a progressive brain disease

c) Alzheimer's means there is a wrong with person's brain and it provides specific the formation of plaques and tangles will be the cause of cognitive decline

d) Alzheimer's is a disease in which brain cells die progressively. This disease is caused by plaque and protein deposits in and around the brain that interferes with normal functioning of brain cells and they begin to die.

e) This disease common in old age but there are cases when even young people have contracted this disease.

f) The affected areas of cognition are memory, attention, language and problem solving. As the disease progresses, disorientation in time starts to surface that poses severe problems 
for the patient and his family. In the later phases of Alzheimer's there is a total breakdown of communication ability, total loss of long term memory and utter confusion.

g) If caused by Alzheimer's, dementia may not be treatable. This particular type of dementia is known as SDAT, or senile dementia of Alzheimer's type (1-5).

\section{Summary}

Old age is commonly associated with loss of cognitive abilities, and when these symptoms worsen interfering with day to day activities, people are often diagnosed with dementia. It is a cluster of symptoms and not a disease while Alzheimer's is a progressive brain disease. Alzheimer's is caused by deposit of plaque and tangles around brain cells and is the most common cause of onset of dementia.

\section{References}

1. (2012a) Prime Minister's challenge on dementia: delivering major improvements in dementia care and research by 2015: A report on progress. Department of Health.

2. (2012b) Prime Minister's challenge on dementia: delivering major improvements in dementia care and research by 2015. Department of Health.

3. (2012c) Department of Health The Mandate: A mandate from the Government to the NHS Commissioning Board April 2013 to March 2015. Department of Health, London.

4. (2013) Department of Health A Mandate from the Government to NHS England: April 2014 to March 2015. Department of Health, London.

5. (2013) NHS England the NHS Constitution: The NHS belongs to us all. Department of Health, London.
Creative Commons Attribution 4.0

International License

For possible submissions Click Here
Submit Article

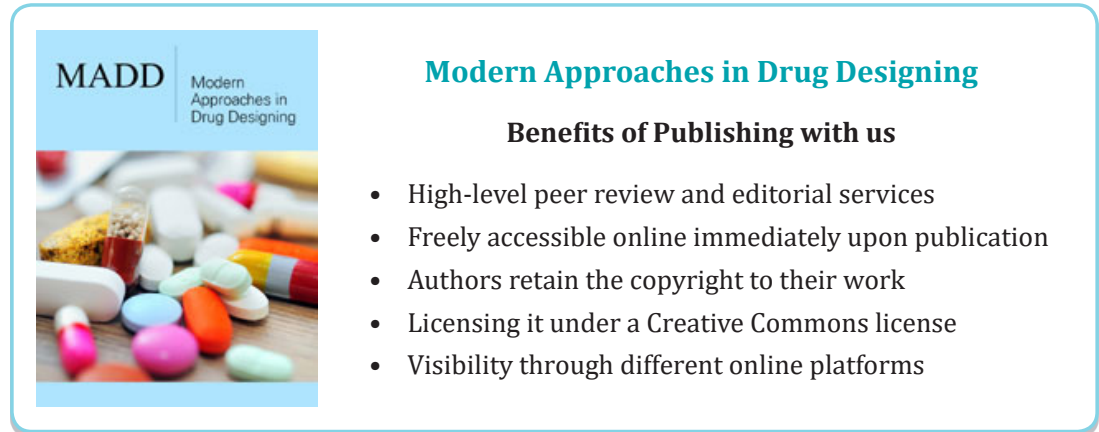

